\title{
Genetic and Epigenetic Mechanisms in Down Syndrome Brain
}

\author{
Jie Lu and Volney Sheen \\ Additional information is available at the end of the chapter \\ http://dx.doi.org/10.5772/52807
}

\section{Introduction}

Down syndrome (DS) is the most common congenital disorder in children, affecting one in 800 live births. While the large number of contiguous genes from a trisomy of chromosome 21 (HSA21) is expected to broadly affect various organ systems during development, significant advances in medicine have been made in this disorder such that those with DS live fairly long life spans. Individuals with DS, however, uniformly demonstrate some degree of mental retardation. Arguably, cognitive disabilities are the more devastating aspect of DS disorder. Part of the cognitive dysfunction lies not only in the progressive neuronal degeneration/cell death and impaired neurogenesis seen in this developmental and degenerative disorder, but also in the reduction in dendrite formation and spine density, resulting in a disruption of synaptic function. These neurological endophenotypes seen in DS may not be merely due to genomic imbalance from triplication of HSA21 genes, but also to additive influences on associated genes within a given network or pathway and modification of gene expressions caused by epigenetic factors including DNA methylation.

Epigenetic factors regulate gene expression largely through DNA modification. Histones are alkaline proteins that package and order DNA into structural nucleosomes. Acetylation and deacetylation, as well as methylation, of histones can modify the density of chromatin and thereby regulate gene transcription through chromatin remodeling. In a parallel manner, biochemical modification of DNA can occur through DNA methylation. This process involves the addition of a methyl group to the 5 position of the cytosine pyrimidine ring or the number 6 nitrogen of the adenine purine ring. DNA methylation at the 5 position of cytosine has the specific effect of reducing gene expression by physically impeding the binding of transcriptional proteins to the gene itself, or by recruiting protein complexes including methyl-CpGbinding domain proteins (MBDs), histone deacetylases (HDACs) and other chromatin 
remodeling proteins. Furthermore, environmental factors such as chemical toxins or oxidative stress can accumulate over time and effect gene transcription. Collectively, these processes modify DNA transcription and may affect many neurodevelopmental processes.

Recent advances in high throughput screening of both mRNA expression and DNA methylation have provided a means to examine changes in gene activation and expression, and to understand the integral relationship between gene clusters in effecting particular pathways. The following review begins by exploring the potential contribution of both genetic and epigenetic factors in regulation of various DS endophenotypes. More specifically, our prior work has examined changes in DS neural progenitor mRNA expression and has led us to identify several important pathways affected in this disorder, such as oxidative stress, mitochondrial dysfunction and gliogenesis. Ongoing studies suggest that changes in DNA methylation in DS may have an effect on oxidative phosphorylation, ubiquitin proteolysis and insulin signaling. The confirmation of mRNA and DNA methylation changes and the clarification of these possible causal pathways may have implications for impaired synaptic function and neurogenesis, which contribute to the cognitive impairment seen in DS. These ongoing studies may further provide informative targets for early pharmaceutical interference to ameliorate the symptoms of mental retardation (MR) in DS.

\section{Genetic mechanisms underlying the DS phenotype}

The triplication of genes on HSA21 causes a wide spectrum of neurological phenotypes in DS, including mental retardation. DS individual displays not only delayed linguistic skills and a relatively low IQ (Intelligent Quotient) but also behavioral issues such as attention-deficit disorder (sometimes with hyperactivity) and autism [1-5]. The cognitive impairments extend further after development, as individuals with DS are more prone to develop Alzheimer's type dementia [6]. In addition, individuals with DS are susceptible to epilepsy in the form of infantile spasms and tonic clonic seizures with myoclonus at early ages [7-9]. These pathological abnormalities in humans are, in part, replicated in DS animal models which show defects in learning, social interactions, memory, and seizures [10-14].

Several genes on HSA21 are implicated in the abnormal neurodevelopment in DS [15]. They can affect cellular function at every stage of neural development, such as proliferation and differentiation of neuroprogenitor cells, neuronal survival and death, synapse formation, maturation and plasticity, as well as myelination. Disruption of each of these pathways can conceptually contribute to the MR seen in DS. Moreover, HSA21 genes have global effects on other genes; a meta-analysis of heterogeneous DS data identified 324 genes with consistent dosage effects, 77 on HSA21 and 247 on non-HSA21 [16]. Therefore, the over-expression of a not so small group of genes on HSA21 may initiate cascades of other signaling pathways on other chromosomes thorough an interactive network. The combinatorial effects from activation of these processes may further contribute to the impairments seen during neurodevelopment in DS. 


\subsection{Genetic mechanisms underlying oxidative stress in DS}

Increased levels of oxidative stress and reactive oxygen species (ROS) have commonly been associated with the DS brain. Free radicals are thought to disrupt the mitochondrial respiratory system, induce apoptosis of neurons and stimulate gliosis, which can further promote neuronal damage. This cyclical pathway may contribute to neuronal losses during neurogenesis as well as neuronal degeneration in adulthood. Several HSA21 genes have been implicated in generation of ROS including DYRK1A, DSCR1, SOD1, ETS2, S100B, APP and BACH1 [15, 17]. Additionally, more recent studies would suggest a synergistic role for various HSA21 genes in induction of this pathological process. For example, over-expression of HSA21 genes APP and $S 100 B$ synergistically increase hydrogen peroxide levels and decrease membrane potential in the mitochondria of human DS neuroprogenitor cells. The combination of a loss of mitochondrial integrity and an increase of oxidative stress promotes apoptosis (changes in caspase and respiratory chain protein expression) and gliosis (increase of GFAP). S100B induction can occur through RAGE (Receptor for Advanced Glycation Endproducts) with consequent activation of JNK/p38 and JAK/STAT signaling. These stress response pathways are known to serve as downstream effectors potentially relevant to reactive gliosis, induction of S100B and glial associated aquaporin $4[18,19]$. Increased levels of S100B and APP further enhance this cyclical cascade by promoting RAGE activation and inflammation with reactive gliosis. Lastly, multiple HSA21 genes have demonstrated enhanced APP-dependent toxic effects on the mitochondria whereas network prediction analyses have shown that four HSA21 proteins are components of the JAK/STAT pathway. These studies imply that an additional 19 HSA21 (among 2004 in total) proteins interact with components in this pathway [20]. These findings reiterate the large cascade of molecules that can be perturbed in a pathway following overexpression of a single gene.

Although oxidative stress in DS patients is considered to be a primary contributor of neurodegeneration such as Alzheimer's Disease (AD) in adult patients, evidences from both human and animal models suggest that these same processes could also affect neurodevelopment and cognitive function at a much earlier age [19, 21-23]. Oxidative stress could therefore not only alter neuronal numbers through degeneration and changes in synaptic plasticity through impaired mitochondrial function, but also affect the generation of neurons during development. In this respect, ongoing effects from over-expression of HSA21 genes likely promote the cognitive dysfunction in DS throughout the lifetime of an individual with this disorder.

\subsection{Genetics mechanisms underlying neurogenesis in DS}

The observation of reduced cortical volume and decreased neuronal numbers in DS patients and animal models could in part be attributed to a reduction in the generation of neurons [24-27]. Over-expression of several HSA21 genes has been implicated in neurogenesis by either altering the rate or proliferation or by changing cell fate specification. By over-expressing HSA21-associated OLIG2, we observed a phenotypic shift in the neural progenitor pool toward glial progenitor phenotypes, accompanied by a corresponding decrease in the number of neuronal progenitors. This change can partly be explained by OLIG2-dependent inhibition of the expression and activity of KCNA3 outward rectifying potassium channels whose activa- 
tion stimulates proliferation of neural progenitors [28]. With respect to proliferation, APP overexpression can antagonistically compete with APPBP1, a protein required for the cell cycle progression from G1 to S phase [29]. Similarly, increased S100B levels stimulate p53 nuclear accumulation and inhibit proliferation [30]. DYRK1A has alternatively been shown to phosphorylate $\mathrm{p} 53$, impair G1/S phase transition and inhibit proliferation [31]. Finally, many HSA21 genes regulate neurogenesis through their effects on NGF, hedgehog, WNT, Notch and insulin signaling pathways [20]. Changes in expression of various HSA21 genes can also regulate subpopulations of progenitors. For example, microarray profiling of DS human neuroprogenitors implicated a defect in interneuron neurogenesis through increased expression of glial progenitor genes such as OLIG1, OLIG2, OMG and COUP-TF1/NR2F1 and downregulation of the interneuron related genes DLX1, DLX2 and DLX5 [32].

\subsection{Genetics mechanisms underlying synaptic formation, maturation and plasticity in DS}

A reduction in brain volume in DS has been attributed to impaired dendritic and synaptic maturation. Dendritic branching and spine number are dramatically reduced in pyramidal neurons in the hippocampus, visual cortex and motor cortex after 4 months postnatal age in individuals with DS [33-35]. The decreased number of spines is usually accompanied by aberrant spine morphology including enlarged or irregular spine heads, and sparse, small, short stalks intermingled with unusually long spines [34, 36]. In addition, DS brains also show changes in expression levels of various synaptic proteins such as decreased SEPT6, SYN1, SNAP-25, SYP and increased SYNJ1 levels [37-41]. Similar morphological changes have been observed in DS animal models and correlate on a molecular level with synaptic protein level changes and functionally with synaptic plasticity defects, observed through LTP, LTD and imbalance of excitatory-inhibitory neurotransmission [42-50]. Many genes on HSA21 (TINM1, SYNJ1, ITSN1; KCNJ6, KCNJ15, KCNE1, KCNE2; NRIP1, ETS2, PCP4, DSCR1, DYRK1A, S100B, $A P P$, OLIG1, OLIG2) have been implicated in the synaptic pathology in DS, and the resulting phenotype likely involves a complex interrelationship between these various genes and their direct or indirect effect on various synaptic proteins [15, 48]. For instance, Dyrk1A overexpression could impair synaptic vesicle endocytosis, reduce dendrite branching and spine density of neurons; these phenotypes might be attributed to Dyrk1A induced hyperphosphorylation of Tau and APP, or other synaptic proteins such as SYNJ1, resulting in impaired hippocampal-dependent learning [51-53]. Moreover, the multiple genetic interactions can additively promote the pathological DS synaptic endophenotype, as more severe defects were observed in Ts65dn mice than in Ts1Cje mice, the former of which contain a larger number of HSA21 associated genes [54].

\section{Epigenetic mechanisms underlying the DS phenotype}

DNA methylation refers to a process of DNA modification that involves the enzymatic transfer of a methyl group from a methyl donor S-adenosylmethionine to carbon 5 of cytosine at $5^{\prime}$ CpG-3' sites. The enzymes carrying out this reaction are called DNA methyltransferases (DNMTs). There are five members in this family: DNMT1, DNMT2, DNMT3A, DNMT3B and 
DNMT3L. DNMT1 is responsible for DNA methylation maintenance while DNMT3A and DNMT3B are involved in de novo DNA methylation. DNMT2 is involved in RNA methylation. DNMT3L (DNA methyltransferase 3-like) does not have enzymatic activity but can stimulate DNMT3A and DNMT3B activation [55-57]. The addition of a methyl group to cytosine may physically impede the binding of transcriptional factors to the gene itself, or by recruiting protein complexes including methyl-CpG-binding protein 2 (MECP2), methyl-CpG-binding domain proteins (MBDs), HDACs and other chromatin remodeling proteins [58]. Alternatively, other enzymes involved in DNA demethylation can reverse this process. These molecules include cytidine deamination (AID, APOBEC) for deamination of cytosine and 5-methylcytosine and hydroxylation (TETs) for converting 5-methylcytosine to 5-hydroxymethylcytosine [59]. DNA modification, especially in the promoter region, by these various regulators may alter gene expression, and thereby affect many physiological processes [60]. In this context, proteins that affect the methylation machinery in DS are likely to alter gene expression and contribute to the DS phenotype.

Epigenetic modification is thought to be an important contributor to development and numerous diseases. Several disorders associated with cognitive impairment such as X-linked alpha-thalassemia mental retardation (ATRX) syndrome, Rett syndrome, and RubinsteinTaybi Syndrome involve some level of disruption in gene regulation through epigenetic effects [61]. The pathology is medicated by different mechanisms including histone modification, chromosome remodeling, small RNAs (siRNA, miRNA and other non-coding RNA) regulation and DNA methylation. More directly, DNMT3B mutations are associated with Immunodeficiency, Centromere instability and Facial anomalies syndrome (ICF) with MR, suggesting that epigenetic alterations in the expression of genes regulating neurogenesis, axon branching, and neuronal migration such as IGF1 and ROBO1, contribute to cognitive impairment [62]. Certain features in DS may, in a similar fashion, be caused by epigenetic changes. For instance, HSA21 genes DYRK1A, BRWD1 and RUNX1 are associated with SWI/SNF complex, a chromatin remodeling complex that regulates the expression of subsets of genes such as HDMTs, HMTs and HDACS- histone modification proteins involved in controlling the expression of various interacting genes [63-65]. HSA21 genes CHAF1B and HMGN1 express chromatin constitutive proteins involved in nucleosome assembly, which controls gene expression through DNA methylation and histone methylation or acetylation [66, 67]. Overexpression of HSA21 derived miRNA miR-155, miR802 in DS brain could also inhibit MECP2 expression, thereby mimicking MECP2 loss of function in Rett syndrome with mental retardation. MECP2 transcriptionally activates and silences CREB1 and MEF2C, genes that are critical in neurodevelopment [68-70]. DNA methylation is another extensively studied epigenetic regulator, being shown as impaired in many diseases. Although its importance has been recognized in cancers, its involvement in neurological disorders such as DS has not been well studied yet.

Several observations suggest that DNA methylation may play an important role in the DS endophenotype. Oxidative stress from over-expression of various HSA21 genes [15] could modulate DNA methylation directly through DNA damage or modification at the CpG sites, thereby preventing normal binding of DNMTs to DNA [71, 72]. DNMT3L is localized on 
HSA21, and its triplication in DS suggests aberrant levels of expression. DNMT3L can form a heterotetramer with DNMT3A, and increased DNMT3L levels could potentially promote release of DNMT3A as well as increase its methylation activity [56]. DNMT3L can also stimulate DNMT3B activity directly $[57,73]$. In addition, Dnmt3a modulates neurogenesis and synaptic plasticity in developing mouse neuroprogenitors and mature neurons by regulating related genes expression, such as Bdnf, Reln, Dlx2, Gbx2, Sp8 and Stat1 [74-77]. It remains to be seen whether other HSA21 genes in addition to DNMT3L can change the expression or activity of various epigenetic modifiers including the DNMTs, MBDs, HDACs or TETs. Overall, epigenetic modification provides an added layer of complexity to the interactive network established from over-expression of genes on HSA21. These modifiers also server as attractive candidates for targeting in DS given the broad effects they potentially have on a particular phenotype.

Next, we will discuss how DNA methylation could be involved in some important neurodevelopmental phenotypes in DS.

\subsection{Epigenetic mechanisms underlying oxidative stress in DS}

While excessive oxidative stress leading to mitochondrial dysfunction is a main feature of DS neurodevelopment, its effects on DNA methylation are not known. Currently no direct evidence demonstrates a role for oxidative stress in regulating DNA methylation changes in DS brain. However, DNA methylation studies from cancer seem to provide some clues. For instance, hydroxyl radicals generated from hydrogen peroxide can cause DNA damage including base modifications, deletions, and breakages, which could consequently interfere with normal function of DNMTs, leading to global hypomethylation in cancer cells [78]. 8OHdG in CpG dinucleotides or the presence of O6-methylguanine could inhibit adjacent cytosine methylation [79-82] by inhibiting DNMTs or MBDs binding [83]. By extension, some of these same pathological mechanisms in cancer cells will likely be relevant in DS.

Methylation changes in the subset of DS genes involved in oxidative stress can contribute to similar phenotypes seen in DS development and disease. For instance, Dnmt1 conditional knockout in neural progenitor cells induced precocious astrogliogenesis through demethylation of S100b, Gfap and Stat1 promoters and activation of the JAK-STAT pathway. Silencing of these genes occurs through Mecp2 mediated inactivation of chromatin remodeling [84], with demethylation resulting in an increase in S100B, GFAP and STAT1 expression. Enhanced expression of these genes further promotes oxidative stress, cell death and gliosis. HSA21 localized APP could also be regulated by promoter dependent DNA methylation. The methylation pattern in the APP promoter is different in different tissues and even in different brain areas [85]. Hypomethylation of APP is found in the cerebral cortex of aging people and $\mathrm{AD}$ patients $[86,87]$; the methylation frequency of $\mathrm{CpG}$ sites on APP promoter in younger people $(26 \%)$ is higher than that in older people $(8 \%)$, suggesting an age related methylation difference [86]. Altered methylation patterns have also been implicated in deregulation of APP processing enzymes PS1 and BACE in AD [88]. Finally, APP can also regulate the expression of other genes such as CTIF, NTX2 and DDR2 through DNA methylation [89]. Overall, these studies suggest that DNMTs appear to play some role in regulation of neurogenesis and 
neurodegeneration, and they do so by regulating several genes on HSA21 involved in oxidative stress. Moreover, HSA21 genes associated with oxidative stress can influence the methylation status of other genes.

\subsection{Epigenetic mechanisms underlying neurogenesis in DS}

DNA methylation regulates neurogenesis. Dnmts are broadly expressed in the brain and are dynamically regulated $[90,91]$. For example, Dnmt1 is expressed in both dividing neuroprogenitors and postmitotic neurons [91, 92]. Dnmt3b is mainly expressed in neuroprogenitor cells during neurogenesis, whereas Dnmt3a is predominantly expressed in maturing brain (including neural precursors, neurons, astrocytes and oligodendrocytes). Dnmt3a expression peaks at three weeks after birth and then declines in adulthood [93, 94]. Dnmt3l directly regulates Dnmt3a and Dnmt3b but is weakly expressed in the brain and does not appear to disrupt normal cortical development. As for function, Hutnick et al used Emx1-cre to conditionally knockdown Dnmt1 exclusively in telencephalic precursors of mice, which induced hypomethylation in excitatory neurons and astrocytes of cortex and hippocampus. The methylation change increased neuronal apoptosis coupled with upregulation of apoptosisrelated genes such as Gadd45a, Casp4 and Ngfr. Loss of Dnmt1 also impaired neurogenesis, maturation, learning and memory and was associated with downregulation of layer specific gene such as Lhx2, neuronal channel genes such as Kcnh5, Kcnj9 and Scnn1a [95]. Interestingly, Gadd45b could contribute to DNA demethylation of pro-neuronal genes such as BDNF and FGF [96]. Studies using postnatal neural stem cells (NSC) in Dnmt3a knockout mice suggest that Dnmt3a promotes non-promoter DNA methylation of neurogenesis genes such as Dlx2, Gbx2 and Sp8 by functionally antagonizing Polycomb repression, resulting in increased expression of these genes [77]. Finally, the expression pattern of Dnmt3b suggests that it may be important for the early phase of neurogenesis (Feng et al., 2005).

DNA methylation may directly effect neural progenitor development in DS. In normal development, Dnmt31 does not appear to have a significant phenotype in the developing mouse cerebral cortex, likely due to its relatively low expression levels in the brain [97, 98], (personal communications, Dr. Yi E. Sun, UCLA). DNMT3L, however, is located on chromosome 21 and its triplication results in aberrantly high levels of expression in DS neuroprogenitors (personal observations). Given that DNMT3L directly regulates both DNMT3A/B and both these proteins have been implicated in neural progenitor development, a pathological role for methylation genes such as DNMT3L in contributing to neurogenesis is likely.

\subsection{Epigenetic mechanisms underlying synaptic formation, maturation and plasticity in DS}

Several HSA21 genes can indirectly regulate epigenetic factors involved in synaptic function. For example, SWI/SNF (SWItch/Sucrose NonFermentable) is a nucleosome-remodeling complex that can destabilize histone-DNA interactions in an ATP-dependent manner. HSA21localized DYRK1A binds the SWI/SNF complex and subsequently induces a coordinated deregulation of multiple genes that are responsible for dendritic growth [65]. Likewise, APP has been shown to alter CPG methylation in three target genes CTIF (CBP80/CBP20-dependent translation initiation factor), NXT2 (nuclear exporting factor 2), and hypermethylated DDR2 
[89]. DDR2 is a tyrosine kinase that functions as a cell surface receptor for fibrillar collagen and regulates cell differentiation, remodeling of the extracellular matrix, cell migration, cell proliferation, and cell cycle progression. More evidences from DNA methylation changing synaptic function come from Dnmt transgenic mice. Dnmt1 and Dnmt3a knockout mice show reduced LTP, deficits in learning and memory and deregulated genes expression associated with synaptic plasticity [74]. Dnmt3a overexpression increases spine density in nucleus accumbens [75]. DNMT3B is the gene mutated in ICF syndrome. Its mutation in lymphoblastoid cell line from patients led to altered genes expression of several systems including regulators of neurogenesis and synaptic function, such as ROBO1, JPH4, FRY, MAP4K4, PCDHGC3, IGF1, SNCA, GABRA4 and BCHE [62]. Methyl-CpG binding protein 1 (MBD1), a member of the methylated DNA-binding protein family, whose mutation leads to reduced neurogenesis, decreased LTP and impaired spatial learning [99]. The involvement of Dnmts and Hdacs in synaptic function is further supported by pharmacological manipulations [100-102]. For instance, Dnmt inhibitors zebularine and 5-aza-2-deoxycytidine can alter DNA methylation at promoters for Reln and Bdnf, and block the induction of LTP in synapses of mouse hippocampus [103].

\section{Global effects of DNA methylation in causing DS phenotypes}

Several reports have shown global DNA methylation changes in DS [104, 105]. For example, individual proteins on HSA21 such as beta amyloid (the protein encoded by HSA21 localized APP) can induce global hypomethylation [106, 107]. Comparison of normal and DS methylation in DS leukocytes and T lymphocytes using microarray-based profiling (MSNP (single nucleotide polymorphism (SNP) chip-based method for profiling DNA methylation) identified a small subset of genes with altered methylation, specific to the DS cell population [104]. Among the genes identified, five candidates (TMEM131, CD3Z, NOD2 and NPDC1) showed correlation with RNA expression, and the methylation changes could be recapitulated by exposing normal lymphocytes to the demethylation drug 5-aza-cytidine. These genes have known or predicted roles in lymphocyte development. In order to gain some insights into the DNA methylation deregulation in DS brain, we have performed some preliminary studies by comparing the methylation profiles of control (CON) and DS frontal cortex from 18 gestational weeks' fetal brain using Illumina 450 Infinium Beadchip assay. Approximately $4 \%$ of the CpG sites showed significant changes at the methylation level. When compared to CON baseline methylated and unmethylated states, more CON unmethylated $\mathrm{CpG}$ sites became methylated in DS than CON methylated states that became unmethylated. Moreover, there was overall greater global hyper versus hypomethylation in DS compared to CON across all chromosomes, except on HSA21. Chromosome 21 actually demonstrated a greater degree of hypo versus hypermethylation in DS (unpublished data). Hypomethylation generally results in increased gene transcription, whereas hypermethylation leads to the converse. Cross comparison of DNA methylation states with the differential mRNA expression genes from previous microarray studies, suggested epigenetic effects on several specific pathways (oxidative phosphorylation, insulin signaling and ubiquitination). 


\subsection{Oxidative phosphorylation}

Oxidative phosphorylation involves cellular metabolism through oxidation to produce ATP. The broad methylation and gene expression changes in this pathway suggest its role as a primary consequence of DS genes' overdose effects. Plasma membrane NADPH oxidase is considered a major producer of ROS in neurons or astrocytes in brain and is activated by S100B through a RAGE-dependent pathway [108-111]. Over-expression of HSA21 genes such as S100B and APP likely promote this pathway and cause cell death in DS neurons [19]. Small amounts of superoxide anion and peroxide are also produced by the electron transport chain in mitochondria [112-114]. The global deregulation of enzymes in this mitochondrial pathway could thus disrupt the balance between oxidant generation and ATP production, result in enhanced ROS generation and lead to diminished ATP levels $[115,116]$. Several DS genes have been implicated in this process. For instance, three HSA21 genes, ATP5J, ATP5O and NDUFV3 are components of ATP synthase and NADH dehydrogenase, though their expression and regulation in DS brain are not known yet. In addition, other HSA21 genes may indirectly affect this pathway. Alternatively, HSA21 gene S100B may target mitochondrial proteins such as p53 and ATPase ATAD3A, thereby assisting the cytoplasmic processing of proteins for proper folding and subcellular localization [117-121]. Another HSA21 gene APP and its product beta amyloid can interact with import receptors to gain entry into mitochondrial compartment, where they accumulate and affect the normal function of this pathway [122, 123]. Finally, gene expression in mitochondrial oxidative phosphorylation may be modulated by DNA methylation. For instance, prenatal protein diet excess or restriction leads to hypomethylation of $\mathrm{CpG}$ sites in the cytochrome C CYCS gene promoter, including those representing putative transcription factor-binding sites. Elevation of this protein can alter electron transport chain function in mitochondria and initiate apoptosis [124]. Our preliminary studies suggest there is a broad change of DNA methylation and genes expression in this oxidative phosphorylation pathway. Given the importance of ATP/ROS metabolism in mitochondrial function, further studies will be needed to understand the epigenetic contribution to this pathway.

\subsection{Insulin signaling}

The insulin/insulin growth factor (IGF)-I pathway is a conserved pathway required for neurogenesis and neuroprotection. It acts through IR/IGF-IR, IRS, and RAS/MAPK or PI3K/AKT in regulating neurogenic cell fate [125]. Decreased levels of IGF-I have been found to associate with growth retardation in DS patients, which could be rescued by GH therapy $[126,127]$. In addition, the insulin receptor knockout mouse suggests that neurons without insulin receptor exhibit significant reduction of Akt and Gsk3beta and increased tau hyperphosphorylation, characteristics of neurotoxicity in DS and AD [128]. Inhibition of the brain insulin signaling pathways have been report in AD brain, with decreased expression of IR, IRS1, IRS2, PI3K and AKT $[129,130]$. This deficiency may, in part, involve DNA methylation changes, given reports of co-localization of Hdac2 with insulin signaling components (Ir, Irs) in postsynaptic glutamatergic neurons of the mouse hippocampus [131]. DNA methylation changes in human DS progenitors (personal observations Lu and Sheen) also suggest that the insulin-associated pathways may contribute to the DS endophenotype during development. 


\subsection{Ubiquitin proteolysis}

The ubiquitin proteasome/lysome system (UPLS) is responsible for the removal of excessive proteins from multiple cellular compartments (especially mitochondria and synapses) in order to maintain normal cellular function [132, 133]. Progression in DS cognitive impairment is associated with accumulation of NF plaques and tangles, which have been shown to contain ubiquitin [134]. Dystrophic neurites in DS also contain ubiquitin and the UPLS-associated molecules PSMA5 and USP5 are upregulated in DS fetal brain [135]. Beta amyloid could regulate synaptic protein degradation and function through ubiquitin pathway [136, 137]. Moreover, several E3 ubiquitin ligases have been shown to promote APP degradation [138, 139]. Additionally, HSA21 located genes AIRE and UBE2G2 are directly involved in the ubiquitin pathway and could contribute to the phenotype. Taken in this context, disruption of mitochondrial function (i.e. through S100B, APP, OLIG2 or disruption of the oxidative phosphorylation pathway) might consequently impair ubiquitin-dependent lysosomal and proteosomal clearance, because it is an ATP-dependent process. Finally, our preliminary studies suggest that DNA methylation may also directly impair ubiquitin function. Loss of ubiquitin function would have direct effects on synaptic function and structure (through beta amyloid or synaptic proteins) but would also possibly enhance oxidative stress and mitochondrial dysfunction. It is interesting to note that the high throughput DNA methylation screen in DS invoked changes in methylation involving three networks (oxidative phosphorylation, insulin signaling, and ubiquitin function), which are highly dependent on one another.

\section{Possible functions of DNMT3L in DS}

Given that DNMT3A and DNMT3B are involved in neurogenesis and synaptic plasticity, HSA21 localized DNMT3L regulates activities of DNMT3A/3B, suggesting that over-expression of this gene will have pathological implications in methylation patterns involved in neural development. Moreover, DNMT3L represses transcription by recruiting HDACs, which may also affect the neurodevelopment [140, 141]. Dnmt3l null mice do not demonstrate a neurological phenotype due to low levels of expression but rather exhibits defects in reproductive organs where it is highly expressed and leads to imprinting and differentiation defect in early stages of embryonic development [97, 98]. DNMT3L (R271Q) variant is associated with significant DNA hypomethylation at the subtelomeric region in healthy human, though it does not seem to cause any diseases [142]. On the other hand, over-expression of DNMT3L in Hela cells mimics the characteristics of iPS cells and carcinogenesis by upregulating SOX2, HOX genes and DNMTs including DNMT1 and DNMT3B expression, suggesting that DNMT3L over-expression may change the DNA methylation profile in later stages of embryo development through activating DNMT3A/DNMT3B when neurogenesis and synapse formation happen [143]. Interestingly, a recently developed DS model Dp(10)1Yey/+ mice harboring a duplication spanning the entire HSA21 syntenic region on mouse chromosome 10 (Mmu10), which contains Dnmt3l and S100b, did not show alterations in cognitive behaviors or hippocampal LTP [144]. However, other mouse transgenic studies with over-expression of select HSA21 genes (i.e. APP and S100b) have shown combinatorial effects in contributing to AD 
features in DS and neuronal survival $[19,145]$. These observations would suggest combinatorial and interactive effects between these genes in contributing to the MR seen in DS. It remains to be seen whether DNMT3L effects on DNMT3A/B are responsible for the part of the preliminary methylation defects seen in the several pathways discussed above. It is also not known how the trisomy of HSA21 genes will effect methylation, but it is highly likely that DNMT3L alters at least a subset of genes. In this respect, it will be important to identify the causative methylation defects due to this single gene, as it will have implications for other DS phenotypes.

\section{Possible targets for pharmaceutical interference}

The epigenetic screens in DS predict involvement of several mutually interactive pathways in contributing to the neurological endophenotype in this disorder: oxidative phosphorylation, insulin signaling, and ubiquitination. Approaches for therapeutic intervention possibly involve either altering the methylation patterns or directly targeting specific pathways.

If global hypermethylation in DS neuroprogenitors is confirmed, then inhibition of DNMT or DNA deamination could be used to rescue or treat the pathological phenotypes. There are two clinical licensed DNMT inhibitors currently used in myelodysplastic syndrome, where they relieve the repression of tumor suppressor genes: 5-aza-cytidine (Vidaza ${ }^{\circledR}$ ) and 5-aza-2'deoxycytidine (Dacogen $®$ ) [59]. In addition, because of the occurrence of hypomethylation, especially on HSA21, it would be desirable to develop a more specific methylation inhibitor/ activator or deamination activator/inhibitor in order to target specific promoters of genes in important pathways.

Dysfunction of the UPLS system causes protein accumulation or over-degradation in cellular organelles. Thus developing activator or inhibitor of proteasomes would have therapeutic meaning. Most currently available activators/inhibitors of the ubiquitin-proteasome pathway directly target the subunits of proteasome, the core of the proteolysis machinery, instead of targeting upstream ubiquitination and recognition of ubiquitinated protein substrates by more specific E3 ubiquitin ligases. Proteasome inhibitors such as Bortezomib, (Velcade®) are in clinical treatment for multiple myeloma [146, 147]. Proteasome activators including 11s activator, Blm10/PA200, and 19s activator are still under research.

Preservation of oxidative phosphorylation pathway and mitochondrial function can be achieved through a new investigational drug EPI-743, currently in phase $2 \mathrm{~B} / 3$ pivotal clinical trials in Inherited Mitochondrial Respiratory Chain Disease [148]. EPI-743 is an orally absorbable small molecule that readily crosses into the central nervous system. It works by targeting an enzyme NADPH quinone oxidoreductase 1 (NQO1). Its mode of action is to synchronize energy generation in mitochondria with the need to counter cellular redox stress [149]. 


\section{Conclusion}

DS is a contiguous gene syndrome which gives rise to MR, dementia, and seizures. These clinical outcomes are mirrored by endophenotypes including increased oxidative stress, decreased neurogenesis and synaptic dysfunction. While these characteristics have largely been attributed to HSA21 gene dosage effects, recent progresses in epigenetic studies have raised the high likelihood that DNA methylation have significant effects on DS neurodevelopment. Methylome screening suggests disruption of pathways involving oxidative phosphorylation, ubiquitination and insulin signaling in DS. Candidate gene analyses suggest that DNMT3L is over-expressed in DS given its location on chromosome 21. Alternatively, other studies have implicated several HSA21 genes in altering methylation sites on genes involved in these same pathways. The pathways invoked through epigenetic regulation contribute directly to known pathological mechanisms identified on prior gene expression profiling such as oxidative stress, gliosis, and mitochondrial dysfunction. In this respect, the DS brain endophenotypes likely arise from the integration of various genetic and epigenetic factors on chromosome 21.

\section{Acknowledgements}

This work was supported by grants to V.L.S from NINDS 1R01NS063997 and NICHD 1R21HD054347.

\section{Author details}

Jie Lu and Volney Sheen*

*Address all correspondence to: vsheen@bidmc.harvard.edu

Department of Neurology, Beth Israel Deaconess Medical Center, Boston, MA, USA

\section{References}

[1] Capone G, Goyal P, Ares W, Lannigan E. Neurobehavioral disorders in children, adolescents, and young adults with Down syndrome. American journal of medical genetics Part C, Seminars in medical genetics. (Review). 2006 Aug 15;142C(3):158-72.

[2] Coe DA, Matson JL, Russell DW, Slifer KJ, Capone GT, Baglio C, et al. Behavior problems of children with Down syndrome and life events. J Autism Dev Disord. (Clinical Trial Controlled Clinical Trial). 1999 Apr;29(2):149-56. 
[3] Gath A, Gumley D. Behaviour problems in retarded children with special reference to Down's syndrome. The British journal of psychiatry : the journal of mental science. 1986 Aug;149:156-61.

[4] Kent L, Evans J, Paul M, Sharp M. Comorbidity of autistic spectrum disorders in children with Down syndrome. Dev Med Child Neurol. (Case Reports). 1999 Mar;41(3): 153-8.

[5] Myers BA, Pueschel SM. Psychiatric disorders in persons with Down syndrome. J Nerv Ment Dis. 1991 Oct;179(10):609-13.

[6] Lott IT. Down's syndrome, aging, and Alzheimer's disease: a clinical review. Annals of the New York Academy of Sciences. (Research Support, U.S. Gov't, P.H.S. Review). 1982;396:15-27.

[7] Arya R, Kabra M, Gulati S. Epilepsy in children with Down syndrome. Epileptic Disord. 2011 Mar 11.

[8] Pueschel SM, Louis S, McKnight P. Seizure disorders in Down syndrome. Archives of neurology. 1991 Mar;48(3):318-20.

[9] Romano C, Tine A, Fazio G, Rizzo R, Colognola RM, Sorge G, et al. Seizures in patients with trisomy 21. American journal of medical genetics Supplement. 1990;7:298-300.

[10] Cortez MA, Shen L, Wu Y, Aleem IS, Trepanier CH, Sadeghnia HR, et al. Infantile spasms and Down syndrome: a new animal model. Pediatr Res. (Research Support, Non-U.S. Gov't). 2009 May;65(5):499-503.

[11] Coussons-Read ME, Crnic LS. Behavioral assessment of the Ts65Dn mouse, a model for Down syndrome: altered behavior in the elevated plus maze and open field. Behavior genetics. (Research Support, Non-U.S. Gov't Research Support, U.S. Gov't, P.H.S.). 1996 Jan;26(1):7-13.

[12] Hyde LA, Frisone DF, Crnic LS. Ts65Dn mice, a model for Down syndrome, have deficits in context discrimination learning suggesting impaired hippocampal function. Behav Brain Res. (Research Support, U.S. Gov't, P.H.S.). 2001 Jan 8;118(1):53-60.

[13] Reeves RH, Irving NG, Moran TH, Wohn A, Kitt C, Sisodia SS, et al. A mouse model for Down syndrome exhibits learning and behaviour deficits. Nature genetics. (Comparative Study Research Support, U.S. Gov't, P.H.S.). 1995 Oct;11(2):177-84.

[14] Westmark CJ, Westmark PR, Malter JS. Alzheimer's disease and Down syndrome rodent models exhibit audiogenic seizures. Journal of Alzheimer's disease : JAD. (Research Support, N.I.H., Extramural Research Support, Non-U.S. Gov't). 2010;20(4): 1009-13.

[15] Lu J, Sheen V. Combinatorial gene effects on the neural progenitor pool in Down syndrome. In: Dey S, editor. Down syndrome Book 1 Genetics and Etiology of Down Syndrome Rijeka, Croatia: InTech; 2011. p. 37-64. 
[16] Vilardell M, Rasche A, Thormann A, Maschke-Dutz E, Perez-Jurado LA, Lehrach H, et al. Meta-analysis of heterogeneous Down Syndrome data reveals consistent genomewide dosage effects related to neurological processes. BMC Genomics. (Meta-Analysis Research Support, Non-U.S. Gov't). 2011;12:229.

[17] Lott IT. Neurological phenotypes for Down syndrome across the life span. Prog Brain Res. (Research Support, N.I.H., Extramural). 2012;197:101-21.

[18] Esposito G, Imitola J, Lu J, De Filippis D, Scuderi C, Ganesh VS, et al. Genomic and functional profiling of human Down syndrome neural progenitors implicates S100B and aquaporin 4 in cell injury. Hum Mol Genet. 2008 Feb 1;17(3):440-57.

[19] Lu J, Esposito G, Scuderi C, Steardo L, Delli-Bovi LC, Hecht JL, et al. S100B and APP Promote a Gliocentric Shift and Impaired Neurogenesis in Down Syndrome Neural Progenitors. PLoS One. 2011;6(7):e22126.

[20] Sturgeon X, Le T, Ahmed MM, Gardiner KJ. Pathways to cognitive deficits in Down syndrome. Prog Brain Res. (Research Support, N.I.H., Extramural Research Support, Non-U.S. Gov't). 2012;197:73-100.

[21] Bambrick LL, Fiskum G. Mitochondrial dysfunction in mouse trisomy 16 brain. Brain research. (Research Support, U.S. Gov't, Non-P.H.S.). 2008 Jan 10;1188:9-16.

[22] Behar TN, Colton CA. Redox regulation of neuronal migration in a Down Syndrome model. Free Radic Biol Med. 2003 Sep 15;35(6):566-75.

[23] Brooksbank BW, Balazs R. Superoxide dismutase, glutathione peroxidase and lipoperoxidation in Down's syndrome fetal brain. Brain Res. 1984 Sep;318(1):37-44.

[24] Ishihara K, Amano K, Takaki E, Shimohata A, Sago H, Epstein CJ, et al. Enlarged brain ventricles and impaired neurogenesis in the Ts1Cje and Ts2Cje mouse models of Down syndrome. Cerebral cortex. (Research Support, Non-U.S. Gov't). 2010 May;20(5): 1131-43.

[25] Schmidt-Sidor B, Wisniewski KE, Shepard TH, Sersen EA. Brain growth in Down syndrome subjects 15 to 22 weeks of gestational age and birth to 60 months. Clin Neuropathol. 1990 Jul-Aug;9(4):181-90.

[26] Sweeney JE, Hohmann CF, Oster-Granite ML, Coyle JT. Neurogenesis of the basal forebrain in euploid and trisomy 16 mice: an animal model for developmental disorders in Down syndrome. Neuroscience. (Research Support, Non-U.S. Gov't Research Support, U.S. Gov't, P.H.S.). 1989;31(2):413-25.

[27] Wisniewski KE, Laure-Kamionowska M, Wisniewski HM. Evidence of arrest of neurogenesis and synaptogenesis in brains of patients with Down's syndrome. N Engl J Med. 1984 Nov 1;311(18):1187-8.

[28] Lu J, Lian G, Zhou H, Esposito G, Steardo L, Delli-Bovi LC, et al. OLIG2 over-expression impairs proliferation of human Down syndrome neural progenitors. Human molecular genetics. 2012 Mar 1. 
[29] Joo Y, Ha S, Hong BH, Kim J, Chang KA, Liew H, et al. Amyloid precursor protein binding protein-1 modulates cell cycle progression in fetal neural stem cells. PLoS One. 2010;5(12):e14203.

[30] Scotto C, Delphin C, Deloulme JC, Baudier J. Concerted regulation of wild-type p53 nuclear accumulation and activation by S100B and calcium-dependent protein kinase C. Mol Cell Biol. 1999 Oct;19(10):7168-80.

[31] Park J, Oh Y, Yoo L, Jung MS, Song WJ, Lee SH, et al. Dyrk1A phosphorylates p53 and inhibits proliferation of embryonic neuronal cells. J Biol Chem. 2010 Oct 8;285(41): 31895-906.

[32] Bhattacharyya A, McMillan E, Chen SI, Wallace K, Svendsen CN. A critical period in cortical interneuron neurogenesis in down syndrome revealed by human neural progenitor cells. Dev Neurosci. 2009;31(6):497-510.

[33] Becker LE, Armstrong DL, Chan F. Dendritic atrophy in children with Down's syndrome. Annals of neurology. 1986 Oct;20(4):520-6.

[34] Marin-Padilla M. Pyramidal cell abnormalities in the motor cortex of a child with Down's syndrome. A Golgi study. The Journal of comparative neurology. (Research Support, U.S. Gov't, P.H.S.). 1976 May 1;167(1):63-81.

[35] Takashima S, Becker LE, Armstrong DL, Chan F. Abnormal neuronal development in the visual cortex of the human fetus and infant with down's syndrome. A quantitative and qualitative Golgi study. Brain research. (Research Support, Non-U.S. Gov't). 1981 Nov 23;225(1):1-21.

[36] Kleschevnikov AM, Belichenko PV, Salehi A, Wu C. Discoveries in Down syndrome: moving basic science to clinical care. Prog Brain Res. (Research Support, N.I.H., Extramural Research Support, Non-U.S. Gov't). 2012;197:199-221.

[37] Arai Y, Ijuin T, Takenawa T, Becker LE, Takashima S. Excessive expression of synaptojanin in brains with Down syndrome. Brain \& development. (Research Support, NonU.S. Gov't). 2002 Mar;24(2):67-72.

[38] Bahn S, Mimmack M, Ryan M, Caldwell MA, Jauniaux E, Starkey M, et al. Neuronal target genes of the neuron-restrictive silencer factor in neurospheres derived from fetuses with Down's syndrome: a gene expression study. Lancet. 2002 Jan 26;359(9303): $310-5$.

[39] Cheon MS, Fountoulakis M, Dierssen M, Ferreres JC, Lubec G. Expression profiles of proteins in fetal brain with Down syndrome. Journal of neural transmission Supplementum. 2001(61):311-9.

[40] Downes EC, Robson J, Grailly E, Abdel-All Z, Xuereb J, Brayne C, et al. Loss of synaptophysin and synaptosomal-associated protein 25-kDa (SNAP-25) in elderly Down syndrome individuals. Neuropathol Appl Neurobiol. (Research Support, NonU.S. Gov't). 2008 Feb;34(1):12-22. 
[41] Weitzdoerfer R, Dierssen M, Fountoulakis M, Lubec G. Fetal life in Down syndrome starts with normal neuronal density but impaired dendritic spines and synaptosomal structure. J Neural Transm Suppl. 2001(61):59-70.

[42] Belichenko PV, Kleschevnikov AM, Masliah E, Wu C, Takimoto-Kimura R, Salehi A, et al. Excitatory-inhibitory relationship in the fascia dentata in the Ts65Dn mouse model of Down syndrome. The Journal of comparative neurology. (Research Support, N.I.H., Extramural Research Support, Non-U.S. Gov't). 2009 Feb 1;512(4):453-66.

[43] Belichenko PV, Kleschevnikov AM, Salehi A, Epstein CJ, Mobley WC. Synaptic and cognitive abnormalities in mouse models of Down syndrome: exploring genotypephenotype relationships. The Journal of comparative neurology. (Research Support, N.I.H., Extramural Research Support, Non-U.S. Gov't). 2007 Oct 1;504(4):329-45.

[44] Belichenko PV, Masliah E, Kleschevnikov AM, Villar AJ, Epstein CJ, Salehi A, et al. Synaptic structural abnormalities in the Ts65Dn mouse model of Down Syndrome. J Comp Neurol. 2004 Dec 13;480(3):281-98.

[45] Benavides-Piccione R, Ballesteros-Yanez I, de Lagran MM, Elston G, Estivill X, Fillat C, et al. On dendrites in Down syndrome and DS murine models: a spiny way to learn. Prog Neurobiol. 2004 Oct;74(2):111-26.

[46] Di Filippo M, Picconi B, Tantucci M, Ghiglieri V, Bagetta V, Sgobio C, et al. Short-term and long-term plasticity at corticostriatal synapses: implications for learning and memory. Behav Brain Res. (Research Support, U.S. Gov't, Non-P.H.S. Review). 2009 Apr 12;199(1):108-18.

[47] Kurt MA, Davies DC, Kidd M, Dierssen M, Florez J. Synaptic deficit in the temporal cortex of partial trisomy 16 (Ts65Dn) mice. Brain Res. 2000 Mar 6;858(1):191-7.

[48] Levenga J, Willemsen R. Perturbation of dendritic protrusions in intellectual disability. Prog Brain Res. (Research Support, Non-U.S. Gov't). 2012;197:153-68.

[49] Perez-Cremades D, Hernandez S, Blasco-Ibanez JM, Crespo C, Nacher J, Varea E. Alteration of inhibitory circuits in the somatosensory cortex of Ts65Dn mice, a model for Down's syndrome. J Neural Transm. 2010 Apr;117(4):445-55.

[50] Pollonini G, Gao V, Rabe A, Palminiello S, Albertini G, Alberini CM. Abnormal expression of synaptic proteins and neurotrophin-3 in the Down syndrome mouse model Ts65Dn. Neuroscience. (Research Support, N.I.H., Extramural Research Support, Non-U.S. Gov't). 2008 Sep 22;156(1):99-106.

[51] Ahn KJ, Jeong HK, Choi HS, Ryoo SR, Kim YJ, Goo JS, et al. DYRK1A BAC transgenic mice show altered synaptic plasticity with learning and memory defects. Neurobiology of disease. (Research Support, Non-U.S. Gov't). 2006 Jun;22(3):463-72.

[52] Benavides-Piccione R, Dierssen M, Ballesteros-Yanez I, Martinez de Lagran M, Arbones ML, Fotaki V, et al. Alterations in the phenotype of neocortical pyramidal cells in the Dyrk1A+/- mouse. Neurobiology of disease. (Research Support, Non-U.S. Gov't). 2005 Oct;20(1):115-22. 
[53] Kim Y, Park J, Song WJ, Chang S. Overexpression of Dyrk1A causes the defects in synaptic vesicle endocytosis. Neurosignals. (Research Support, Non-U.S. Gov't). 2010;18(3):164-72.

[54] Herault Y, Duchon A, Velot E, Marechal D, Brault V. The in vivo Down syndrome genomic library in mouse. Prog Brain Res. (Research Support, Non-U.S. Gov't). 2012;197:169-97.

[55] Bestor TH. The DNA methyltransferases of mammals. Human molecular genetics. (Research Support, Non-U.S. Gov't Research Support, U.S. Gov't, P.H.S. Review). 2000 Oct;9(16):2395-402.

[56] Jurkowska RZ, Rajavelu A, Anspach N, Urbanke C, Jankevicius G, Ragozin S, et al. Oligomerization and binding of the Dnmt3a DNA methyltransferase to parallel DNA molecules: heterochromatic localization and role of Dnmt3L. The Journal of biological chemistry. (Research Support, Non-U.S. Gov't). 2011 Jul 8;286(27):24200-7.

[57] Suetake I, Shinozaki F, Miyagawa J, Takeshima H, Tajima S. DNMT3L stimulates the DNA methylation activity of Dnmt3a and Dnmt3b through a direct interaction. J Biol Chem. 2004 Jun 25;279(26):27816-23.

[58] Hashimoto H, Vertino PM, Cheng X. Molecular coupling of DNA methylation and histone methylation. Epigenomics. (Research Support, N.I.H., Extramural Review). 2010 Oct;2(5):657-69.

[59] Carey N, Marques CJ, Reik W. DNA demethylases: a new epigenetic frontier in drug discovery. Drug Discov Today. (Review). 2011 Aug;16(15-16):683-90.

[60] Gopalakrishnan S, Van Emburgh BO, Robertson KD. DNA methylation in development and human disease. Mutat Res. (Research Support, N.I.H., Extramural Review). 2008 Dec 1;647(1-2):30-8.

[61] Sanchez-Mut JV, Huertas D, Esteller M. Aberrant epigenetic landscape in intellectual disability. Prog Brain Res. 2012;197:53-71.

[62] Jin B, Tao Q, Peng J, Soo HM, Wu W, Ying J, et al. DNA methyltransferase 3B (DNMT3B) mutations in ICF syndrome lead to altered epigenetic modifications and aberrant expression of genes regulating development, neurogenesis and immune function. Human molecular genetics. (Comparative Study Research Support, N.I.H., Extramural Research Support, Non-U.S. Gov't). 2008 Mar 1;17(5):690-709.

[63] Bakshi R, Hassan MQ, Pratap J, Lian JB, Montecino MA, van Wijnen AJ, et al. The human SWI/SNF complex associates with RUNX1 to control transcription of hematopoietic target genes. J Cell Physiol. (Research Support, N.I.H., Extramural). 2010 Nov; 225(2):569-76.

[64] Huang ZQ, Li J, Sachs LM, Cole PA, Wong J. A role for cofactor-cofactor and cofactorhistone interactions in targeting p300, SWI/SNF and Mediator for transcription. The EMBO journal. (Research Support, U.S. Gov't, Non-P.H.S. Research Support, U.S. Gov't, P.H.S.). 2003 May 1;22(9):2146-55. 
[65] Lepagnol-Bestel AM, Zvara A, Maussion G, Quignon F, Ngimbous B, Ramoz N, et al. DYRK1A interacts with the REST/NRSF-SWI/SNF chromatin remodelling complex to deregulate gene clusters involved in the neuronal phenotypic traits of Down syndrome. Hum Mol Genet. 2009 Apr 15;18(8):1405-14.

[66] Reese BE, Bachman KE, Baylin SB, Rountree MR. The methyl-CpG binding protein MBD1 interacts with the p150 subunit of chromatin assembly factor 1 . Molecular and cellular biology. (Research Support, U.S. Gov't, P.H.S.). 2003 May;23(9):3226-36.

[67] Ueda T, Postnikov YV, Bustin M. Distinct domains in high mobility group N variants modulate specific chromatin modifications. The Journal of biological chemistry. (Research Support, N.I.H., Intramural). 2006 Apr 14;281(15):10182-7.

[68] Keck-Wherley J, Grover D, Bhattacharyya S, Xu X, Holman D, Lombardini ED, et al. Abnormal microRNA expression in Ts65Dn hippocampus and whole blood: contributions to Down syndrome phenotypes. Developmental neuroscience. (Research Support, N.I.H., Extramural Research Support, Non-U.S. Gov't Research Support, U.S. Gov't, Non-P.H.S.). 2011;33(5):451-67.

[69] Kuhn DE, Nuovo GJ, Martin MM, Malana GE, Pleister AP, Jiang J, et al. Human chromosome 21-derived miRNAs are overexpressed in down syndrome brains and hearts. Biochemical and biophysical research communications. (Research Support, N.I.H., Extramural). 2008 Jun 6;370(3):473-7.

[70] Kuhn DE, Nuovo GJ, Terry AV, Jr., Martin MM, Malana GE, Sansom SE, et al. Chromosome 21-derived microRNAs provide an etiological basis for aberrant protein expression in human Down syndrome brains. The Journal of biological chemistry. (Research Support, N.I.H., Extramural Research Support, Non-U.S. Gov't). 2010 Jan 8;285(2):1529-43.

[71] Donkena KV, Young CY, Tindall DJ. Oxidative stress and DNA methylation in prostate cancer. Obstet Gynecol Int. 2010;2010:302051.

[72] Franco R, Schoneveld O, Georgakilas AG, Panayiotidis MI. Oxidative stress, DNA methylation and carcinogenesis. Cancer Lett. (Research Support, N.I.H., Intramural Research Support, Non-U.S. Gov't Review). 2008 Jul 18;266(1):6-11.

[73] Chedin F, Lieber MR, Hsieh CL. The DNA methyltransferase-like protein DNMT3L stimulates de novo methylation by Dnmt3a. Proceedings of the National Academy of Sciences of the United States of America. (Research Support, Non-U.S. Gov't Research Support, U.S. Gov't, P.H.S.). 2002 Dec 24;99(26):16916-21.

[74] Feng J, Zhou Y, Campbell SL, Le T, Li E, Sweatt JD, et al. Dnmt1 and Dnmt3a maintain DNA methylation and regulate synaptic function in adult forebrain neurons. Nature neuroscience. (Comparative Study Research Support, N.I.H., Extramural Research Support, Non-U.S. Gov't). 2010 Apr;13(4):423-30. 
[75] LaPlant Q, Vialou V, Covington HE, 3rd, Dumitriu D, Feng J, Warren BL, et al. Dnmt3a regulates emotional behavior and spine plasticity in the nucleus accumbens. Nature neuroscience. (Research Support, N.I.H., Extramural). 2010 Sep;13(9):1137-43.

[76] Levenson JM, Roth TL, Lubin FD, Miller CA, Huang IC, Desai P, et al. Evidence that DNA (cytosine-5) methyltransferase regulates synaptic plasticity in the hippocampus. The Journal of biological chemistry. (In Vitro Research Support, N.I.H., Extramural). 2006 Jun 9;281(23):15763-73.

[77] Wu H, Coskun V, Tao J, Xie W, Ge W, Yoshikawa K, et al. Dnmt3a-dependent nonpromoter DNA methylation facilitates transcription of neurogenic genes. Science. (Research Support, N.I.H., Extramural Research Support, Non-U.S. Gov't). 2010 Jul 23;329(5990):444-8.

[78] Wachsman JT. DNA methylation and the association between genetic and epigenetic changes: relation to carcinogenesis. Mutat Res. (Review). 1997 Apr 14;375(1):1-8.

[79] Hepburn PA, Margison GP, Tisdale MJ. Enzymatic methylation of cytosine in DNA is prevented by adjacent O6-methylguanine residues. The Journal of biological chemistry. (Research Support, Non-U.S. Gov't). 1991 May 5;266(13):7985-7.

[80] Tan NW, Li BF. Interaction of oligonucleotides containing 6-O-methylguanine with human DNA (cytosine-5-)-methyltransferase (published erratumm appears in Biochemistry 1992 Aug 4;31(30):7008). Biochemistry. (Research Support, Non-U.S. Gov't). 1990 Oct 2;29(39):9234-40.

[81] Turk PW, Laayoun A, Smith SS, Weitzman SA. DNA adduct 8-hydroxyl-2'-deoxyguanosine (8-hydroxyguanine) affects function of human DNA methyltransferase. Carcinogenesis. (Comparative Study Research Support, Non-U.S. Gov't Research Support, U.S. Gov't, P.H.S.). 1995 May;16(5):1253-5.

[82] Weitzman SA, Turk PW, Milkowski DH, Kozlowski K. Free radical adducts induce alterations in DNA cytosine methylation. Proceedings of the National Academy of Sciences of the United States of America. (Research Support, U.S. Gov't, P.H.S.). 1994 Feb 15;91(4):1261-4.

[83] Valinluck V, Tsai HH, Rogstad DK, Burdzy A, Bird A, Sowers LC. Oxidative damage to methyl-CpG sequences inhibits the binding of the methyl-CpG binding domain (MBD) of methyl-CpG binding protein 2 (MeCP2). Nucleic acids research. (Research Support, Non-U.S. Gov't Research Support, U.S. Gov't, P.H.S.). 2004;32(14):4100-8.

[84] Fan G, Martinowich K, Chin MH, He F, Fouse SD, Hutnick L, et al. DNA methylation controls the timing of astrogliogenesis through regulation of JAK-STAT signaling. Development. 2005 Aug;132(15):3345-56.

[85] Rogaev EI, Lukiw WJ, Lavrushina O, Rogaeva EA, St George-Hyslop PH. The upstream promoter of the beta-amyloid precursor protein gene (APP) shows differential patterns of methylation in human brain. Genomics. (Comparative Study Research Support, Non-U.S. Gov't). 1994 Jul 15;22(2):340-7. 
[86] Tohgi H, Utsugisawa K, Nagane Y, Yoshimura M, Genda Y, Ukitsu M. Reduction with age in methylcytosine in the promoter region -224 approximately -101 of the amyloid precursor protein gene in autopsy human cortex. Brain Res Mol Brain Res. (Research Support, Non-U.S. Gov't). 1999 Jul 5;70(2):288-92.

[87] West RL, Lee JM, Maroun LE. Hypomethylation of the amyloid precursor protein gene in the brain of an Alzheimer's disease patient. J Mol Neurosci. (Comparative Study Research Support, Non-U.S. Gov't Research Support, U.S. Gov't, P.H.S.). 1995;6(2): $141-6$.

[88] Fuso A, Seminara L, Cavallaro RA, D'Anselmi F, Scarpa S. S-adenosylmethionine/ homocysteine cycle alterations modify DNA methylation status with consequent deregulation of PS1 and BACE and beta-amyloid production. Molecular and cellular neurosciences. (Research Support, Non-U.S. Gov't). 2005 Jan;28(1):195-204.

[89] Sung HY, Choi EN, Ahn Jo S, Oh S, Ahn JH. Amyloid protein-mediated differential DNA methylation status regulates gene expression in Alzheimer's disease model cell line. Biochemical and biophysical research communications. (Research Support, NonU.S. Gov't). 2011 Nov 4;414(4):700-5.

[90] Feng J, Fouse S, Fan G. Epigenetic regulation of neural gene expression and neuronal function. Pediatr Res. (Research Support, N.I.H., Extramural Review). 2007 May;61(5 Pt 2):58R-63R.

[91] Goto K, Numata M, Komura JI, Ono T, Bestor TH, Kondo H. Expression of DNA methyltransferase gene in mature and immature neurons as well as proliferating cells in mice. Differentiation. (Research Support, Non-U.S. Gov't). 1994 Apr;56(1-2):39-44.

[92] Brooks PJ, Marietta C, Goldman D. DNA mismatch repair and DNA methylation in adult brain neurons. The Journal of neuroscience : the official journal of the Society for Neuroscience. 1996 Feb 1;16(3):939-45.

[93] Feng J, Chang H, Li E, Fan G. Dynamic expression of de novo DNA methyltransferases Dnmt3a and Dnmt3b in the central nervous system. Journal of neuroscience research. (Comparative Study Research Support, N.I.H., Extramural Research Support, U.S. Gov't, P.H.S.). 2005 Mar 15;79(6):734-46.

[94] Watanabe D, Uchiyama K, Hanaoka K. Transition of mouse de novo methyltransferases expression from Dnmt3b to Dnmt3a during neural progenitor cell development. Neuroscience. (Comparative Study In Vitro Research Support, Non-U.S. Gov't). 2006 Oct 27;142(3):727-37.

[95] Hutnick LK, Golshani P, Namihira M, Xue Z, Matynia A, Yang XW, et al. DNA hypomethylation restricted to the murine forebrain induces cortical degeneration and impairs postnatal neuronal maturation. Hum Mol Genet. 2009 Aug 1;18(15):2875-88.

[96] Ma DK, Jang MH, Guo JU, Kitabatake Y, Chang ML, Pow-Anpongkul N, et al. Neuronal activity-induced Gadd45b promotes epigenetic DNA demethylation and adult 
neurogenesis. Science. (Research Support, N.I.H., Extramural Research Support, NonU.S. Gov't). 2009 Feb 20;323(5917):1074-7.

[97] Arima T, Hata K, Tanaka S, Kusumi M, Li E, Kato K, et al. Loss of the maternal imprint in Dnmt3Lmat-/- mice leads to a differentiation defect in the extraembryonic tissue. Developmental biology. (Research Support, Non-U.S. Gov't). 2006 Sep 15;297(2):361-73.

[98] Bourc'his D, Xu GL, Lin CS, Bollman B, Bestor TH. Dnmt3L and the establishment of maternal genomic imprints. Science. (Research Support, Non-U.S. Gov't Research Support, U.S. Gov't, P.H.S.). 2001 Dec 21;294(5551):2536-9.

[99] Zhao X, Ueba T, Christie BR, Barkho B, McConnell MJ, Nakashima K, et al. Mice lacking methyl-CpG binding protein 1 have deficits in adult neurogenesis and hippocampal function. Proceedings of the National Academy of Sciences of the United States of America. (Research Support, Non-U.S. Gov't Research Support, U.S. Gov't, P.H.S.). 2003 May 27;100(11):6777-82.

[100] Lubin FD, Roth TL, Sweatt JD. Epigenetic regulation of BDNF gene transcription in the consolidation of fear memory. The Journal of neuroscience : the official journal of the Society for Neuroscience. (Comparative Study Research Support, N.I.H., Extramural Research Support, Non-U.S. Gov't). 2008 Oct 15;28(42):10576-86.

[101] Miller CA, Campbell SL, Sweatt JD. DNA methylation and histone acetylation work in concert to regulate memory formation and synaptic plasticity. Neurobiol Learn Mem. (Research Support, N.I.H., Extramural Research Support, Non-U.S. Gov't). 2008 May; 89(4):599-603.

[102] Miller CA, Sweatt JD. Covalent modification of DNA regulates memory formation. Neuron. (Research Support, N.I.H., Extramural Research Support, Non-U.S. Gov't). 2007 Mar 15;53(6):857-69.

[103] Levenson JM, Qiu S, Weeber EJ. The role of reelin in adult synaptic function and the genetic and epigenetic regulation of the reelin gene. Biochimica et biophysica acta. (Review). 2008 Aug;1779(8):422-31.

[104] Kerkel K, Schupf N, Hatta K, Pang D, Salas M, Kratz A, et al. Altered DNA methylation in leukocytes with trisomy 21. PLoS Genet. (Research Support, N.I.H., Extramural). 2010 Nov;6(11):e1001212.

[105] Loudin MG, Wang J, Leung HC, Gurusiddappa S, Meyer J, Condos G, et al. Genomic profiling in Down syndrome acute lymphoblastic leukemia identifies histone gene deletions associated with altered methylation profiles. Leukemia. (Research Support, N.I.H., Extramural Research Support, Non-U.S. Gov't Validation Studies). 2011 Oct; 25(10):1555-63.

[106] Chen KL, Wang SS, Yang YY, Yuan RY, Chen RM, Hu CJ. The epigenetic effects of amyloid-beta(1-40) on global DNA and neprilysin genes in murine cerebral endothelial cells. Biochemical and biophysical research communications. 2009 Jan 2;378(1):57-61. 
[107] Mastroeni D, Grover A, Delvaux E, Whiteside C, Coleman PD, Rogers J. Epigenetic changes in Alzheimer's disease: decrements in DNA methylation. Neurobiology of aging. (Randomized Controlled Trial Research Support, N.I.H., Extramural Research Support, Non-U.S. Gov't). 2010 Dec;31(12):2025-37.

[108] Anantharam V, Kaul S, Song C, Kanthasamy A, Kanthasamy AG. Pharmacological inhibition of neuronal NADPH oxidase protects against 1-methyl-4-phenylpyridinium $(\mathrm{MPP}+)$-induced oxidative stress and apoptosis in mesencephalic dopaminergic neuronal cells. Neurotoxicology. (Research Support, N.I.H., Extramural). 2007 Sep; 28(5):988-97.

[109] Donato R, Sorci G, Riuzzi F, Arcuri C, Bianchi R, Brozzi F, et al. S100B's double life: intracellular regulator and extracellular signal. Biochimica et biophysica acta. (Research Support, Non-U.S. Gov't Review). 2009 Jun;1793(6):1008-22.

[110] Glass MJ, Huang J, Oselkin M, Tarsitano MJ, Wang G, Iadecola C, et al. Subcellular localization of nicotinamide adenine dinucleotide phosphate oxidase subunits in neurons and astroglia of the rat medial nucleus tractus solitarius: relationship with tyrosine hydroxylase immunoreactive neurons. Neuroscience. (Comparative Study Research Support, N.I.H., Extramural). 2006 Dec 1;143(2):547-64.

[111] Serrano F, Kolluri NS, Wientjes FB, Card JP, Klann E. NADPH oxidase immunoreactivity in the mouse brain. Brain research. (Research Support, U.S. Gov't, P.H.S.). 2003 Oct 24;988(1-2):193-8.

[112] Finkel T, Holbrook NJ. Oxidants, oxidative stress and the biology of ageing. Nature. (Review). 2000 Nov 9;408(6809):239-47.

[113] Raha S, McEachern GE, Myint AT, Robinson BH. Superoxides from mitochondrial complex III: the role of manganese superoxide dismutase. Free Radic Biol Med. (Research Support, Non-U.S. Gov't). 2000 Jul 15;29(2):170-80.

[114] Raha S, Robinson BH. Mitochondria, oxygen free radicals, disease and ageing. Trends Biochem Sci. (Research Support, Non-U.S. Gov't Review). 2000 Oct;25(10):502-8.

[115] Echtay KS, Roussel D, St-Pierre J, Jekabsons MB, Cadenas S, Stuart JA, et al. Superoxide activates mitochondrial uncoupling proteins. Nature. 2002 Jan 3;415(6867):96-9.

[116] Kadenbach B, Ramzan R, Vogt S. Degenerative diseases, oxidative stress and cytochrome c oxidase function. Trends in molecular medicine. (Research Support, Non-U.S. Gov't). 2009 Apr;15(4):139-47.

[117] Donato R. Intracellular and extracellular roles of S100 proteins. Microsc Res Tech. 2003 Apr 15;60(6):540-51.

[118] Gilquin B, Cannon BR, Hubstenberger A, Moulouel B, Falk E, Merle N, et al. The calcium-dependent interaction between $\mathrm{S} 100 \mathrm{~B}$ and the mitochondrial AAA ATPase ATAD3A and the role of this complex in the cytoplasmic processing of ATAD3A. Mol Cell Biol. 2010 Jun;30(11):2724-36. 
[119] Leclerc E, Sturchler E, Vetter SW. The S100B/RAGE Axis in Alzheimer's Disease. Cardiovasc Psychiatry Neurol. 2010;2010:539581.

[120] Lin J, Blake M, Tang C, Zimmer D, Rustandi RR, Weber DJ, et al. Inhibition of p53 transcriptional activity by the S100B calcium-binding protein. J Biol Chem. 2001 Sep 14;276(37):35037-41.

[121] Mihara M, Erster S, Zaika A, Petrenko O, Chittenden T, Pancoska P, et al. p53 has a direct apoptogenic role at the mitochondria. Mol Cell. 2003 Mar;11(3):577-90.

[122] Devi L, Anandatheerthavarada HK. Mitochondrial trafficking of APP and alpha synuclein: Relevance to mitochondrial dysfunction in Alzheimer's and Parkinson's diseases. Biochim Biophys Acta. 2010 Jan;1802(1):11-9.

[123] Manczak M, Anekonda TS, Henson E, Park BS, Quinn J, Reddy PH. Mitochondria are a direct site of A beta accumulation in Alzheimer's disease neurons: implications for free radical generation and oxidative damage in disease progression. Hum Mol Genet. 2006 May 1;15(9):1437-49.

[124] Altmann S, Murani E, Schwerin M, Metges CC, Wimmers K, Ponsuksili S. Somatic cytochrome c (CYCS) gene expression and promoter-specific DNA methylation in a porcine model of prenatal exposure to maternal dietary protein excess and restriction. Br J Nutr. (Comparative Study Research Support, Non-U.S. Gov't). 2012 Mar;107(6): 791-9.

[125] Bateman JM, McNeill H. Insulin/IGF signalling in neurogenesis. Cell Mol Life Sci. (Review). 2006 Aug;63(15):1701-5.

[126] Anneren G, Tuvemo T, Carlsson-Skwirut C, Lonnerholm T, Bang P, Sara VR, et al. Growth hormone treatment in young children with Down's syndrome: effects on growth and psychomotor development. Arch Dis Child. (Clinical Trial Controlled Clinical Trial Research Support, Non-U.S. Gov't). 1999 Apr;80(4):334-8.

[127] Barreca A, Rasore Quartino A, Acutis MS, Ponzani P, Damonte G, Miani E, et al. Assessment of growth hormone insulin like growth factor-I axis in Down's syndrome. J Endocrinol Invest. (Clinical Trial Controlled Clinical Trial Research Support, NonU.S. Gov't). 1994 Jun;17(6):431-6.

[128] Schubert M, Gautam D, Surjo D, Ueki K, Baudler S, Schubert D, et al. Role for neuronal insulin resistance in neurodegenerative diseases. Proceedings of the National Academy of Sciences of the United States of America. (Research Support, Non-U.S. Gov't Research Support, U.S. Gov't, P.H.S.). 2004 Mar 2;101(9):3100-5.

[129] Liu Y, Liu F, Grundke-Iqbal I, Iqbal K, Gong CX. Deficient brain insulin signalling pathway in Alzheimer's disease and diabetes. J Pathol. (Research Support, N.I.H., Extramural Research Support, Non-U.S. Gov't). 2011 Sep;225(1):54-62.

[130] Rivera EJ, Goldin A, Fulmer N, Tavares R, Wands JR, de la Monte SM. Insulin and insulin-like growth factor expression and function deteriorate with progression of 
Alzheimer's disease: link to brain reductions in acetylcholine. Journal of Alzheimer's disease : JAD. (Research Support, N.I.H., Extramural). 2005 Dec;8(3):247-68.

[131] Yao ZG, Liu Y, Zhang L, Huang L, Ma CM, Xu YF, et al. Co-location of HDAC2 and Insulin Signaling Components in the Adult Mouse Hippocampus. Cell Mol Neurobiol. 2012 Jun 26.

[132] Livnat-Levanon N, Glickman MH. Ubiquitin-proteasome system and mitochondria reciprocity. Biochimica et biophysica acta. (Research Support, Non-U.S. Gov't Review). 2011 Feb;1809(2):80-7.

[133] Mabb AM, Ehlers MD. Ubiquitination in postsynaptic function and plasticity. Annu Rev Cell Dev Biol. (Research Support, N.I.H., Extramural Research Support, Non-U.S. Gov't Review). 2010 Nov 10;26:179-210.

[134] Mattiace LA, Kress Y, Davies P, Ksiezak-Reding H, Yen SH, Dickson DW. Ubiquitinimmunoreactive dystrophic neurites in Down's syndrome brains. Journal of neuropathology and experimental neurology. (Research Support, U.S. Gov't, P.H.S.). 1991 Sep; 50(5):547-59.

[135] Engidawork E, Juranville JF, Fountoulakis M, Dierssen M, Lubec G. Selective upregulation of the ubiquitin-proteasome proteolytic pathway proteins, proteasome zeta chain and isopeptidase $\mathrm{T}$ in fetal Down syndrome. Journal of neural transmission Supplementum. (Research Support, Non-U.S. Gov't). 2001(61):117-30.

[136] Roselli F, Livrea P, Almeida OF. CDK5 is essential for soluble amyloid beta-induced degradation of GKAP and remodeling of the synaptic actin cytoskeleton. PloS one. (Research Support, Non-U.S. Gov't). 2011;6(7):e23097.

[137] Roselli F, Tirard M, Lu J, Hutzler P, Lamberti P, Livrea P, et al. Soluble beta-amyloid1-40 induces NMDA-dependent degradation of postsynaptic density-95 at glutamatergic synapses. The Journal of neuroscience : the official journal of the Society for Neuroscience. (Research Support, N.I.H., Extramural Research Support, Non-U.S. Gov't). 2005 Nov 30;25(48):11061-70.

[138] Kaneko M, Saito R, Okuma Y, Nomura Y. Possible involvement of ubiquitin ligase HRD1 insolubilization in amyloid beta generation. Biol Pharm Bull. (Research Support, Non-U.S. Gov't). 2012;35(2):269-72.

[139] Watanabe T, Hikichi Y, Willuweit A, Shintani Y, Horiguchi T. FBL2 Regulates Amyloid Precursor Protein (APP) Metabolism by Promoting Ubiquitination-Dependent APP Degradation and Inhibition of APP Endocytosis. The Journal of neuroscience : the official journal of the Society for Neuroscience. 2012 Mar 7;32(10):3352-65.

[140] Aapola U, Liiv I, Peterson P. Imprinting regulator DNMT3L is a transcriptional repressor associated with histone deacetylase activity. Nucleic Acids Res. 2002 Aug 15;30(16):3602-8. 
[141] Deplus R, Brenner C, Burgers WA, Putmans P, Kouzarides T, de Launoit Y, et al. Dnmt3L is a transcriptional repressor that recruits histone deacetylase. Nucleic Acids Res. 2002 Sep 1;30(17):3831-8.

[142] El-Maarri O, Kareta MS, Mikeska T, Becker T, Diaz-Lacava A, Junen J, et al. A systematic search for DNA methyltransferase polymorphisms reveals a rare DNMT3L variant associated with subtelomeric hypomethylation. Human molecular genetics. (Research Support, Non-U.S. Gov't). 2009 May 15;18(10):1755-68.

[143] Gokul G, Ramakrishna G, Khosla S. Reprogramming of HeLa cells upon DNMT3L overexpression mimics carcinogenesis. Epigenetics. (Research Support, Non-U.S. Gov't). 2009 Jul 1;4(5):322-9.

[144] Yu T, Liu C, Belichenko P, Clapcote SJ, Li S, Pao A, et al. Effects of individual segmental trisomies of human chromosome 21 syntenic regions on hippocampal long-term potentiation and cognitive behaviors in mice. Brain research. (In Vitro Research Support, N.I.H., Extramural Research Support, Non-U.S. Gov't). 2010 Dec 17;1366:162-71.

[145] Mori T, Koyama N, Arendash GW, Horikoshi-Sakuraba Y, Tan J, Town T. Overexpression of human S100B exacerbates cerebral amyloidosis and gliosis in the Tg2576 mouse model of Alzheimer's disease. Glia. 2010 Feb;58(3):300-14.

[146] Huang L, Chen CH. Proteasome regulators: activators and inhibitors. Curr Med Chem. (Research Support, N.I.H., Extramural Review). 2009;16(8):931-9.

[147] Stadtmueller BM, Hill CP. Proteasome activators. Molecular cell. (Research Support, N.I.H., Extramural Review). 2011 Jan 7;41(1):8-19.

[148] Enns GM, Kinsman SL, Perlman SL, Spicer KM, Abdenur JE, Cohen BH, et al. Initial experience in the treatment of inherited mitochondrial disease with EPI-743. Mol Genet Metab. (Clinical Trial Research Support, N.I.H., Extramural Research Support, NonU.S. Gov't). 2012 Jan;105(1):91-102.

[149] Shrader WD, Amagata A, Barnes A, Enns GM, Hinman A, Jankowski O, et al. alphaTocotrienol quinone modulates oxidative stress response and the biochemistry of aging. Bioorg Med Chem Lett. 2011 Jun 15;21(12):3693-8. 
